\title{
MODOS DE RACIOCÍNIO DOS ESTUDANTES QUANDO A 3ㄹ LEI DE NEWTON INTERVÉM NO ESTUDO DO FENÔMENO DO ATRITO
}

\section{THE STUDENTS' WAYS OF REASONING WHEN THE NEWTON'S $3^{\text {TH }}$ LAW INTERVENES IN THE STUDY OF THE FRICTION PHENOMENON}

\author{
Helena Caldas ${ }^{1}$ e Edith Saltiel ${ }^{2}$
}

\begin{abstract}
Resumo
Este trabalho investiga os modos de raciocínio de uma população variada, quer pelo seu país de origem quer pelo seu nível de ensino, em situações onde a $3^{\text {a }}$ lei de Newton intervém no estudo do fenômeno do atrito sólido seco. Por meio das análises de vários questionários descrevendo situações físicas onde dois ou três corpos estão em contato, são colocadas em evidência as características destes modos de raciocínio. Ainda, uma análise de livros didáticos mostra que os estudantes encontram, na grande maioria destes, elementos que alimentam o tipo de resultados encontrados. Como decorrência do conjunto dos resultados obtidos, algumas recomendações sobre o tratamento do tema do atrito serão sugeridas, no que se relaciona especificamente com os aspectos abordados no trabalho.
\end{abstract}

\section{Summary}

This work investigates the ways of reasoning of a diverse population, as much for their country of origin as for their teaching level, in situations where the Newton's $3^{\text {rd }}$ law intervenes in the study of the dry solid friction phenomenon. By means of the analyses of several questionnaires describing physical situations where two or three bodies are in contact, the characteristics of these ways of reasoning will stand out. Still, an analysis of text books shows that the students find elements, in the great majority of these books, which back up the type of results found. As a consequence of the amount of the results obtained, some recommendations on the treatment of the friction will be suggested specifically regarding the aspects approached in the work.

Palavras-chave: Ensino de Física, Atrito, $3^{\mathrm{a}}$ lei de Newton

Key words: Physics Education, Friction, Newton's $3^{\text {th }}$ Law

\footnotetext{
${ }^{1}$ Departamento de Física - Centro de Ciências Exatas - Universidade Federal do Espírito Santo - UFES Campus de Goiabeiras, Av. Fernando Ferrari, s/n.o; 29.060 - 900, Vitória - ES - Brasil - E-mail: helenac@npd.ufes.br

${ }^{2}$ Université Denis Diderot - Paris VII - Laboratoire de Didactique des Sciences Physiques - LDSP, Paris, França - E-mail: esaltiel@ccr.jussieu.fr
} 
Versão do Título: Modos de raciocínio dos estudantes: atrito e $3^{\mathrm{a}}$ lei de Newton

\section{Introdução}

Os fenômenos do atrito de escorregamento (atrito cinético ou dinâmico) e de não escorregamento (atrito estático) entre as zonas de contato não lubrificadas dos sólidos (atrito sólido seco), cujos efeitos manifestam-se continuamente na nossa vida quotidiana, são, em maior ou menor profundidade, sempre abordados nos diversos níveis de ensino de Física.

Entretanto, que seja do nosso conhecimento, os numerosos e diversos trabalhos de investigação que relatam as idéias dos estudantes em Mecânica (entre outros, Viennot 1979, 1989, 1996, Saltiel \& Malgrange 1980, Maloney 1984, Ogborn 1985, Terry \& Saltiel 1985, Menigaux 1986; Whitelock 1991; Boyle \& Maloney 1991, Thornton \& Sokoloff 1998), de modo geral não se ocupam especificamente sobre o tema do fenômeno do atrito sólido seco, existindo, portanto, uma ausência de trabalhos que se dediquem à investigação do impacto que o estudo dos vários aspectos desse fenômeno pode trazer para os estudantes.

Por outro lado, estes trabalhos, em particular aqueles que concernem a $3^{\text {a }}$ lei Newton (por exemplo, os trabalhos de Viennot, Menigaux ou Maloney) embora não tratem especificamente das forças de atrito, nos permitem prever que os estudantes podem encontrar uma série de dificuldades produzidas pela presença do atrito em situações físicas nas quais vários sólidos estão em contato: dificuldades ligadas à aplicação desta lei na análise das forças de contato exercidas sobre os sólidos e à localização do ponto de aplicação destas forças.

Viennot (1979, 1989, 1996) ou Maloney (1984) nos mostram como, em geral, esta lei é mal compreendida e aplicada: por exemplo, para os estudantes, em situações de não equilíbrio, a reação pode ser considerada diferente da ação.

Por outro lado, os estudantes têm bastante dificuldade em localizar corretamente sobre que objeto as forças de contato agem. Sobre este assunto Menigaux (1986) mostrou que:

“...observa-se assim que, tanto para as forças de pressão como para as forças de tração, uma porcentagem importante de alunos esquematiza as forças de uma interação, invertendo os objetos de aplicação das forças."

Ou ainda, outro aspeto do mesmo problema:

“...espontaneamente, os alunos caracterizam os objetos de uma interação em objeto “ativo" e objeto 'passivo'... para os alunos, o objeto 'ativo' tem uma ação sobre o objeto 'passivo', é a ação da lei da ação e reação. Entretanto, a reação, no sentido proposto por esta lei, que é a ação do objeto 'passivo' sobre o ‘ativo' Ihes é menos evidente”.

A questão da localização das forças é também abordada por Viennot (1989):

“... existe confusão entre a idéia da contabilidade das forças exercidas sobre um mesmo objeto, efetuada para compreender ou prever o movimento deste objeto, e a idéia de comparar (lei da ação e reação) as forças que se exercem sobre objetos diferentes.

Uma tal confusão favorece e/ou é mantida pelo fato de que os objetos sobre os quais as forças se aplicam não são claramente localizados; um ponto de contato entre os objetos 
pertence tanto a um quanto a outro: "fixar" neste contato uma força não é suficiente para especificar sobre que objeto a força se exerce."

Assim, as principais tendências dos modos de raciocínio dos estudantes sobre a problemática da $3^{\underline{a}}$ lei de Newton identificadas nas diferentes investigações e susceptíveis de terem implicações no estudo do atrito, podem ser resumidas da seguinte forma:

- em situações de não equilíbrio, a reação pode ser considerada diferente da ação;

- na representação das forças de uma interação, tanto para as forças de pressão como para as forças de tração, os objetos de aplicação das forças podem ser invertidos;

- caracterização dos corpos de uma interação em objeto "ativo" e objeto "passivo", sendo que o objeto "ativo" tem uma ação sobre o objeto "passivo", não ocorrendo o contrário;

- $\quad$ aplicação da 3a lei de Newton sobre um mesmo objeto, isto é, o par de forças ação e reação são exercidas no mesmo corpo e não em corpos distintos;

- os corpos sobre os quais as forças se aplicam não são claramente localizados e, desta forma, um ponto de contato entre os corpos pode pertencer tanto a um quanto a outro corpo;

Efetivamente, a aplicação desta lei é bastante importante na apreensão do fenômeno do atrito, pois, dados dois sólidos $S_{1}$ e $S_{2}$ em contato (considerando-se estes indeformáveis), 0 estudo do conjunto das ações de contato entre estes sólidos permite afirmar que:

- As ações de contato exercidas por um dos sólidos sobre o outro (por exemplo $S_{1}$ sobre $S_{2}$ ) são representadas (modeladas) pela resultante das forças de contato que o sólido $S_{1}$ exerce sobre $\mathrm{S}_{2}$, isto é, $\mathbf{R}_{\mathbf{1 2}}{ }^{3[1]}$.

- A lei da ações recíprocas (3a lei de Newton) impõe que, se o sólido $S_{1}$ exerce uma força $\mathbf{R}_{\mathbf{1 2}}$ sobre o sólido $S_{2}$, então o sólido $S_{2}$ exercerá uma força $\mathbf{R}_{\mathbf{2 1}}$ sobre o sólido $S_{1}$ : $\mathbf{R}_{\mathbf{1 2}}$ e $\mathbf{R}_{\mathbf{2 1}}$ são iguais em módulo, têm a mesma direção, mas sentidos contrários $\left(\mathbf{R}_{\mathbf{1 2}}=-\mathbf{R}_{\mathbf{2 1}}\right)$.

- Na presença de atrito, cada resultante das forças de contato $\mathbf{R}$ é sempre inclinada de um certo ângulo em relação à normal às superfícies em contato ${ }^{4[2]}$. $\mathbf{N}$ (força normal) e $\mathbf{T}$ (força de atrito) representam as componentes de $\mathbf{R}$, respectivamente, normal e tangencial a cada uma destas superfícies. Teremos, portanto, $\mathbf{R}=\mathbf{T}+\mathbf{N}$.

\footnotetext{
${ }^{3[1]}$ As grandezas vetoriais serão sempre representados em negrito.

${ }^{4[2]}$ O termo "superfícies em contato" será sempre empregado no sentido geral: a superfície de contato entre dois sólidos poderá ser um ponto, uma linha ou uma superfície plana.
} 


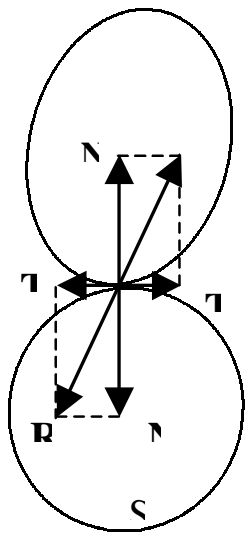

Figura 1: Forças
Assim, conforme a figura 1, para os dois sólidos $S_{1}$ e $S_{2}$, a ação do sólido $S_{2}$ sobre o sólido $S_{1}$ é dada por,

$$
\mathbf{R}_{21}=\mathbf{T}_{21}+\mathbf{N}_{\mathbf{2 1}}
$$

e a ação do sólido $S_{1}$ sobre o sólido $S_{2}$ é dada por,

$$
R_{12}=T_{12}+N_{12}
$$

Como $\mathbf{R}_{12}=-\mathbf{R}_{\mathbf{2 1}}$, então,

$$
N_{12}=-N_{21} \text { e } T_{12}=-T_{21}
$$

- - Quando o atrito é considerado desprezível (supostamente nulo), a resultante das ações de contato $\mathbf{R}$ reduz-se somente à força normal às superfícies de contato: $\mathbf{R}=\mathbf{N}$ e $\mathbf{T}=$ 0 .

Assim, para os dois sólidos $S_{1}$ e $S_{2}$, a ação de $S_{2}$ sobre $S_{1}$ é dada por $\mathbf{N}_{21}$ e a ação de $S_{1}$ sobre $S_{2}$ é dada por $\mathbf{N}_{12}$, sendo $\mathbf{N}_{12}=-\mathbf{N}_{\mathbf{2 1}}$.

Como consideramos os sólidos indeformáveis (uma abstração teórica da realidade), significa que admitimos que os contatos entre os sólidos são contatos teóricos, podendo estes se fazer segundo um ponto, uma linha ou uma superfície plana.

Supondo, por exemplo, um contato pontual teórico: o contato entre duas superfícies de curvaturas diferentes, pode ter lugar, geometricamente, em um ponto P. Neste ponto, dois pontos materiais $P_{1}$ e $P_{2}$ pertencendo, respectivamente, aos corpos $S_{1}$ e $S_{2}$, estão em contato.

Assim, é preciso distinguir o ponto $\mathrm{P}$, puramente geométrico, dos pontos materiais $\mathrm{P}_{1} \mathrm{e}$ $P_{2}$, coincidentes com o ponto $P$ no instante considerado e pertencendo, respectivamente, aos sólidos $S_{1}$ e $S_{2}$ (figura 2). 


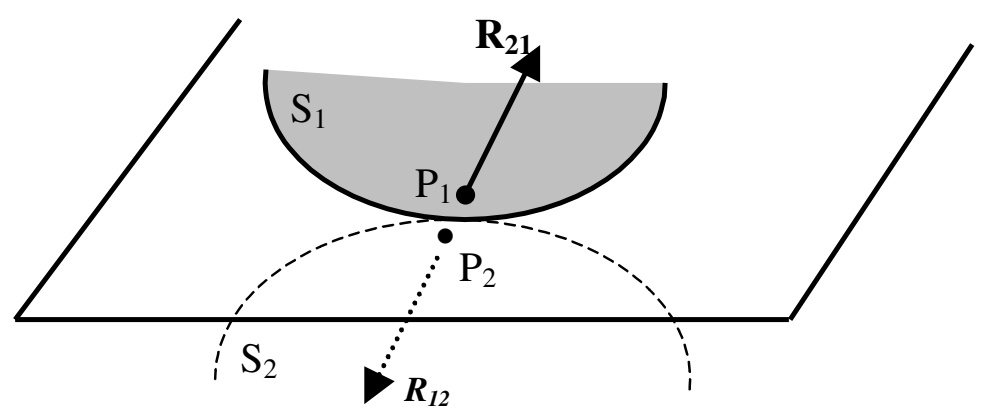

Figura 2: Contato pontual teórico

$\mathbf{R}_{21}$ é a resultante das forças de contato aplicada por $P_{2}$ sobre $P_{1}$ e dirigida para o "interior" de $S_{1}$. Obviamente, segundo a $3^{\text {a }}$ lei de Newton, $\mathbf{R}_{\mathbf{1 2}}$ seria a resultante das forças de contato aplicada por $P_{1}$ sobre $P_{2}$ e dirigida para o "interior" de $S_{2}$, sendo $\mathbf{R}_{\mathbf{1 2}}$ e $\mathbf{R}_{\mathbf{2 1}}$, duas forças de mesmo módulo e direção, porém de sentidos opostos.

Desta forma, é preciso compreender que a um fenômeno de atrito existente entre as superfícies em contato, correspondem duas resultantes das forças de contato, cada uma sendo exercida sobre cada um dos sólidos em contato e "ligadas" pela $3^{\text {a }}$ lei de Newton; cada resultante, inclinada de um certo ângulo em relação à normal às superfícies em contato, é sempre dirigida para o interior de cada sólido e admite duas componentes: uma, perpendicular às superfícies de contato, a força normal e a outra, tangencial a estas mesmas superfícies, a força de atrito.

\section{Problemática do estudo}

Dado o acima exposto, estamos interessados em conhecer quais são as idéias dos estudantes quando confrontados com situações físicas onde existe atrito (estático ou cinético) entre os sólidos em contato, procurando responder aqui, às seguintes questões específicas de estudo:

- Para os estudantes, quando dois ou mais sólidos estão em contato, uns sobre os outros, a terceira lei de Newton é aplicada, no que diz respeito às forças de contato exercidas sobre os sólidos?

- Para os estudantes, qual a localização destas forças (ponto de aplicação) nos sólidos em estudo?

- Em quais sólidos, para os estudantes, são exercidas as forças de contato tangenciais (forças de atrito) e perpendiculares (forças normais) às superfícies em contato?

Com o propósito geral de se verificar a consistência do estudo analítico e a importância ou relevância dos resultados obtidos, certas opções metodológicas foram feitas e certos aspectos foram considerados na concepção do trabalho, tais como: 
- a construção de vários questionários, onde diferentes situações são propostas para estudar a mesma problemática, a fim de verificar se, mudando-se a situação, os elementos de respostas que permeiam as justificativas são os mesmos e, caso eventualmente não sejam, analisar o que poderia estar afetando essa mudança;

- a aplicação dos questionários em estágios sucessivos, isto é, a análise de um questionário deveria, em geral, determinar a elaboração e aplicação do outro, a fim de confirmar, infirmar, esclarecer ou completar os resultados anteriormente obtidos;

- a aplicação de questionários, se possível, a uma população não desprezível numericamente e oriunda de diferentes países ${ }^{5[3]}$;

- a aplicação de questionários diferentes, mas envolvendo a mesma problemática, a diferentes grupos populacionais, quer culturalmente, quer em nível de ensino formal, a fim de verificar a existência ou não de diferenças importantes no tipo de justificativas apresentadas e, seja qual for o caso, principalmente verificar que elementos de resposta ainda permaneciam, apesar das "variações" em questão.

Assim, foram propostos vários questionários a estudantes (todos tendo já estudado o atrito) de diferentes países (França, Brasil, Portugal, Espanha e Itália) e de diferentes níveis de estudo, desde estudantes do Ensino Médio ( $2^{\circ}$ e $3^{\circ}$ anos) até estudantes do Ensino Superior (1ำ e $2^{\circ}$ anos) e a professores do Ensino Médio (Espanha). No total, 738 pessoas foram interrogadas.

Estes questionários resumem a situação física na qual 2 blocos (questionários $A_{1}$ e $A_{2}$ ) ou 3 blocos (questionário $B$ ) são colocados uns sobre os outros, o conjunto repousando sobre uma superfície horizontal de atrito desprezível. Em todas as situações propostas, uma força externa é exercida sobre um de blocos, de tal forma que (fig. 3):

- Ou os corpos movem-se uns em relação aos outros (acelerações diferentes em relação à superfície horizontal) com um atrito (aqui cinético) entre superfícies em contato: questionários denominados $A_{1 c}, A_{2 c}$ e $B_{c}$ (em anexo);

- Ou os corpos movem-se solidariamente (a mesma aceleração em relação à superfície horizontal) com um atrito (aqui estático) entre superfícies em contato: questionários denominados $A_{1 e}, A_{2 e}{ }^{6[4]}$

${ }^{5[3]}$ Como é de conhecimento geral, várias revistas internacionalmente reconhecidas na área, não recomendam, nas suas diretrizes para a elaboração de trabalhos empíricos, que estes sejam realizados com pequenos grupos populacionais. Interpretamos essa diretriz, como um certo consenso entre os pesquisadores da área, com o qual concordamos.

${ }^{[[4]}$ As perguntas a estes questionários são do mesmo tipo daquelas dos questionários $A_{1 c}$ e $A_{2 c}$ (em anexo), aplicadas a um atrito estático. 


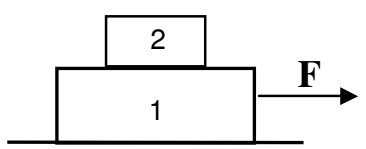

$\mathrm{A}_{1 \mathrm{c}}$ e $\mathrm{A}_{1 \mathrm{e}}$

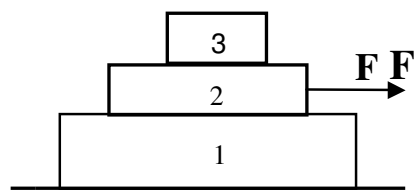

$\mathrm{B}_{\mathrm{c}}$

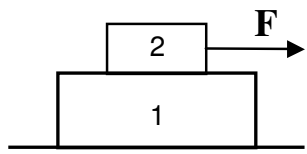

$\mathrm{A}_{2 \mathrm{c}}$ e $\mathrm{A}_{2 \mathrm{e}}$

Figura 3: Situações físicas dos questionários

As questões propostas permitiram conhecer, por meio dos diagramas de forças e das perguntas descritivas, como os estudantes representavam as forças exercidas sobre os blocos, qual era a localização destas forças ("entre" os blocos, no bloco inferior ou no bloco superior) e em que bloco elas agiam.

Assim, o que nos interessa aqui analisar por intermédio das questões propostas nos questionários, são tão somente os aspectos capazes de responder às questões de estudo atrás enunciadas e para as quais o quadro teórico inicialmente descrito serve de suporte.

Quanto à população interrogada, esta foi repartida de acordo com a tabela 1:

Tabela 1 - População interrogada segundo o país de origem, tipo de questionário aplicado e o nível de ensino

\begin{tabular}{|c|c|c|c|}
\hline País de origem & $\begin{array}{l}\text { População } \\
\text { (N) }\end{array}$ & $\begin{array}{c}\text { Questionários/ } \\
\text { Situações }\end{array}$ & Nível de Ensino \\
\hline França & $\begin{array}{l}36 \\
89 \\
64 \\
63 \\
75\end{array}$ & $\begin{array}{l}A_{1 c} \text { (“2 blocos") } \\
A_{2 c} \text { ("2 blocos") } \\
A_{1 e} \text { ("2 blocos") } \\
A_{2 e} \text { ("2 blocos") } \\
B_{c} \text { ("3 blocos") }\end{array}$ & $\begin{array}{l}\text { Superior } \\
\text { Superior } \\
\text { Superior/Médio } \\
\text { Superior/Médio } \\
\text { Superior }\end{array}$ \\
\hline Brasil & $\begin{array}{l}58 \\
92 \\
64\end{array}$ & $\begin{array}{l}A_{1 c} \text { ("2 blocos") } \\
A_{2 c} \text { ("2 blocos") } \\
B_{c} \text { ("3 blocos") }\end{array}$ & $\begin{array}{l}\text { Superior } \\
\text { Superior } \\
\text { Superior }\end{array}$ \\
\hline Portugal & $\begin{array}{l}11 \\
38 \\
\end{array}$ & $\begin{array}{l}A_{1 c} \text { ("2 blocos") } \\
A_{2 c} \text { ("2 blocos") }\end{array}$ & \begin{tabular}{|l|} 
Médio \\
Médio \\
\end{tabular} \\
\hline Itália & 100 & $A_{1 c}$ (“2 blocos”) & Médio \\
\hline Espanha & 48 & $\mathrm{~B}_{\mathrm{c}}$ ("3 blocos") & $\begin{array}{l}\text { Professores do } \\
\text { Ensino Médio }\end{array}$ \\
\hline Total & 738 & 5 & 3 \\
\hline
\end{tabular}


Os questionários foram todos anônimos e a população interrogada respondia individualmente às questões propostas com auxílio de lápis e borracha, entregando espontaneamente os questionários respondidos num tempo médio de 25 minutos.

As instruções antes da sua aplicação foram sempre as mesmas: era dito à população que seria interrogada, que se tratava de um instrumento de pesquisa na área de Ensino de Física onde as justificativas eram o essencial das respostas e onde as análises preocupavamse fundamentalmente com o tipo de justificativas dadas e não, exatamente, em corrigir o "certo" e o "errado". justificativas.

Nesta perspectiva, a população era convidada a detalhar o máximo possível as suas

\section{Resultados}

Em geral, nos 738 questionários propostos, não foram notadas diferenças substanciais nas respostas, quer de um questionário para outro, quer de uma população para outra, ou ainda, quer de um tipo de atrito para o outro.

Assim, optamos por apresentar os principais resultados obtidos para o conjunto dos questionários e questões.

\section{III.1 Representação e identificação das forças}

A análise do conjunto de respostas formado pela representação das forças e a sua identificação, permitiu-nos distinguir três categorias de respostas que denominamos de:

- Forças solitárias: respostas nas quais só aparecia uma ÚNICA força (tangente ou normal às superfícies em contato), enquanto que, de acordo com a terceira lei de Newton, deveriam aparecer duas forças com a mesma direção e em sentidos opostos, cada uma agindo em cada um dos corpos em contato.

- Forças casadas: respostas nas quais aparecia corretamente um par de forças (tangente ou normal às superfícies em contato), indicando uma relação entre elas conforme a terceira lei de Newton (par ação e reação).

- Inclassificável (I): sem resposta, respostas ilegíveis ou incompreensíveis.

Os resultados obtidos encontram-se reunidos na tabela 2:

Tabela 2 - Forças de contato: categorias de respostas

\begin{tabular}{|c|c|c|c|c|c|}
\hline \multirow{2}{*}{$\begin{array}{c}\text { População } \\
\text { (N) }\end{array}$} & \multirow[b]{2}{*}{ Quest. } & \multirow{2}{*}{$\begin{array}{c}\text { Forças de } \\
\text { contato }\end{array}$} & \multicolumn{3}{|c|}{ Categorias de Respostas } \\
\hline & & & $\begin{array}{c}\text { Forças } \\
\text { Solitárias }\end{array}$ & $\begin{array}{l}\text { Forças } \\
\text { Casadas }\end{array}$ & I \\
\hline \multirow{2}{*}{$N=738$} & \multirow{2}{*}{$\begin{array}{c}A_{1 c}, A_{2 c} \\
A_{1 e}, A_{2 e}, \\
B_{c}\end{array}$} & $\begin{array}{c}\text { Força de } \\
\text { Atrito }\end{array}$ & $64,0 \%$ & $26,0 \%$ & $10,0 \%$ \\
\hline & & $\begin{array}{c}\text { Força } \\
\text { Normal }\end{array}$ & $75,1 \%$ & $19,9 \%$ & $5,0 \%$ \\
\hline
\end{tabular}

Como se pode observar, a grande maioria da população interrogada pertence à 
categoria de "forças solitárias", tanto para as forças de atrito como para as forças normais.

\section{III.2 Localização das forças}

A análise feita nas forças desenhadas, permitiu destinguir as seguintes categorias, quanto à localização das forças de atrito e das forças normais nos sólidos em estudo:

- Interface dos blocos: forças desenhadas na interface dos blocos (solitárias ou casadas);

Bloco de cima: forças solitárias desenhadas sobre o bloco "de cima" (blocos 2 em relação aos blocos 1, em todos os questionários e o bloco 3 em relação ao bloco 2, no questionário $\mathrm{B}_{\mathrm{c}}$ ), isto é, o ponto de aplicação das forças é claramente localizado sobre este bloco;

- Bloco de baixo: forças solitárias desenhadas sobre o bloco "de baixo" (blocos 1 em relação aos blocos 2, em todos os questionários e o bloco 2 em relação ao bloco 3, no questionário $B_{c}$ ), isto é, o ponto de aplicação das forças é claramente localizado sobre este bloco;

- Cada bloco: forças casadas desenhadas sobre "cada" bloco, isto é, o ponto de aplicação de cada uma das forças é claramente localizado sobre cada um dos blocos;

A tabela 3 reúne, então, os resultados obtidos quanto à localização das forças de contato:

Tabela 3 - Localização das forças de contato: categorias de respostas

\begin{tabular}{|c|c|c|c|c|c|c|}
\hline \multirow[b]{2}{*}{ Quest. } & \multirow{2}{*}{$\begin{array}{l}\text { População } \\
\text { que } \\
\text { desenhou } \\
\text { forças } \\
\text { (N) }\end{array}$} & \multirow[b]{2}{*}{$\begin{array}{c}\text { Forças } \\
\text { de } \\
\text { contato }\end{array}$} & \multicolumn{4}{|c|}{$\begin{array}{l}\text { Localização das forças de contato: categorias de } \\
\text { respostas }\end{array}$} \\
\hline & & & $\begin{array}{c}\text { Interface } \\
\text { dos blocos } \\
\text { (forças solitárias } \\
\text { ou casadas) }\end{array}$ & $\begin{array}{c}\text { Bloco } \\
\text { de cima } \\
\text { (forças } \\
\text { solitárias) }\end{array}$ & $\begin{array}{c}\text { Blocos } \\
\text { debaixo } \\
\text { (forças } \\
\text { solitárias) }\end{array}$ & $\begin{array}{c}\text { Cada } \\
\text { bloco } \\
\text { (forças } \\
\text { casadas) }\end{array}$ \\
\hline \multirow{2}{*}{$\begin{array}{c}A_{1 \mathrm{c}}, A_{2 \mathrm{c}}, \\
\mathrm{A}_{1 \mathrm{e}}, \mathrm{A}_{2 \mathrm{e}}, \\
\mathrm{B}_{\mathrm{c}}\end{array}$} & $N=664$ & $\begin{array}{l}\text { Força de } \\
\text { Atrito }\end{array}$ & $65,0 \%$ & $25,0 \%$ & $0,0 \%$ & $10,0 \%$ \\
\hline & $N=701$ & $\begin{array}{l}\text { Força } \\
\text { Normal }\end{array}$ & - & $79,0 \%$ & $0,0 \%$ & $21,0 \%$ \\
\hline
\end{tabular}

Assim, constata-se que para as forças de atrito, aproximadamente dois terços da população desenha estas forças na interface de contato dos blocos (quer as forças sejam solitárias ou casadas); menos de um terço, desenha a força de atrito solitária sobre o bloco "de cima"; uma pequena minoria, desenha as forças de atrito casadas distinguindo bem os corpos nos quais estas forças seriam aplicadas e ninguém desenha a força de atrito solitária sobre 0 bloco "debaixo".

Observe-se que para toda a população que traça forças normais solitárias $(75,1 \%)$, o ponto de aplicação destas forças é sempre localizado sobre o bloco "de cima", representando a força que o bloco "debaixo" exerce sobre o bloco "de cima" ( $\uparrow$ ); assim, ninguém desenha a 
força normal solitária sobre o bloco "debaixo", o que representaria a força que o bloco "de cima" exerceria sobre aquele bloco $(\downarrow)$.

Em resumo, o ponto de aplicação de todas as forças normais solitárias é sempre localizado no bloco que está sobre a interface de contato dos blocos e o sentido atribuído a estas forças é sempre aquele debaixo para cima $(\uparrow)$.

Para aqueles que desenham forças normais casadas, o ponto de aplicação de cada força é claramente localizado em cada bloco e os sentidos de cada força são corretamente atribuídos.

\section{III.3 Onde as forças são exercidas?}

Dados os resultados atrás descritos, as seguintes questões se colocam:

- Que representam para os estudantes as forças solitárias desenhadas? Sobre que objetos elas agem? Somente sobre um dos objetos em contato ou sobre os dois?

$\mathrm{Na}$ análise das justificativas, inesperadas argumentações eram explicitadas por uma parte importante da população interrogada, quando esta explicava o sentido por ela atribuído à força de atrito que se exercia sobre os blocos que se encontravam "sob" os outros blocos (blocos 1 para todos os questionários e o bloco 2 em relação ao bloco 3 para o questionário $B_{c}$ ); o mesmo tipo de argumentações explicitava-se e repetia-se ainda, nas respostas à pergunta 4 dos questionários $A_{1 c}$ e $B_{c}$.

Assim, $\mathbf{5 1} \%$ das pessoas interrogadas, no conjunto dos questionários e das questões, declara explicitamente nas justificativas que a força de atrito que se exerceria sobre os blocos localizados sob a interface de contato (blocos "debaixo") não existe, ou que, se ela existe, não tem efeito sobre estes blocos, enquanto que, quando se trata dos blocos localizados sobre esta interface (blocos "de cima"), ninguém utiliza tal argumento: a força de atrito sobre estes blocos sempre existe e exerce sempre um efeito sobre eles.

Citemos, como ilustração, o tipo de justificativas encontradas nos estudantes que desenham forças solitárias ${ }^{7[5]}$, observando que nas figuras representamos apenas as forças de atrito $\left(\mathbf{f}_{\mathbf{a}}\right)$ traçadas pela população interrogada:

- Questionário $A_{1 c}$, questão 2, sobre o movimento do bloco 1:

${ }^{7[5]}$ As frases "em negrito" nas citações das justificativas da população interrogada, são por nós destacadas a fim de colocar em evidência os aspectos importantes para os objetivos do estudo. 


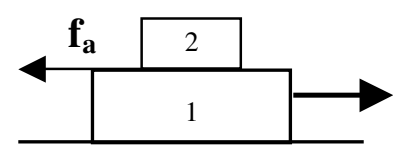

Figura 4: Forças traçadas pela população
"Claro que não, dado que não há atrito sob o bloco $m_{1}$, então este está livre para todo o movimento. A força de atrito que existe sobre o bloco não desempenha nenhum papel quanto ao movimento deste." (fig. 4)

"Não, a força de atrito não se opõe ao movimento, porque a força de atrito aplica-se entre os blocos (2) e (1) e a única coisa que pode perturbar o movimento seria 0 atrito entre (1) e a mesa." (fig. 4)

- Questionário $A_{1 c}$, questão 4, sobre a modificação ou não do movimento dos blocos 1 e 2, se o atrito fosse aumentado entre estes blocos:

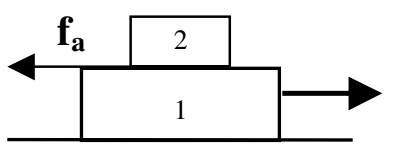

Figura 5: Forças traçadas pela população
"O movimento do bloco 1 não mudará porque 0 atrito deste bloco com o solo não muda. O movimento de 2 será modificado porque o aumento do atrito com 1 vai provocar uma dificuldade maior em relação ao deslocamento de 2." (fig. 5)

- Questionário $A_{2 c}$, questão 2, sobre o movimento do bloco 1:

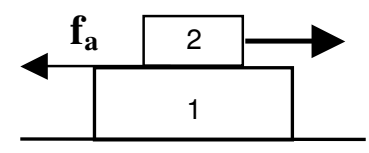

Figura 6: Forças traçadas pela população
"O bloco $m_{1}$ desloca-se para a direita porque a força de $F$ tem este sentido. A força de atrito sobre $m_{1}$ não se opõe ao movimento porque não existe um atrito que age sobre (1): o atrito mesa/m $m_{1}$ é nulo." (fig. 6)

"Por causa do atrito entre os blocos, o movimento de $m_{1}$ será o mesmo que o da força $F$ sobre $m_{2}$. Se existisse atrito entre $m_{1}$ e a mesa, o atrito seria de sentido contrário ao movimento de $m_{1}$. O bloco move-se somente por causa do atrito com o bloco 2 (porque as superfícies aderem umas às outras) pois o atrito funciona como uma ponte de transmissão. Não podemos esquecer que $m_{1}$ se deslocará livremente sobre a superfície na qual ele repousa, acompanhando assim o sentido da força F sobre (2)." (fig. 6)

Questionário $\mathrm{B}_{\mathrm{c}}$, questão 2, sobre o movimento do bloco 1: 




Figura 7: Forças traçadas pela população

Questionário $B_{c}$, questão 4 , sobre a modificação ou não do movimento dos e ela só age sobre $\boldsymbol{m}_{2}$ e não sobre $\boldsymbol{m}_{1}$." (fig. 7)

"Não, porque não há forças exercidas sobre o bloco (1). A força que pode ter conseqüências no movimento, é o atrito solo/m, que, neste caso, é nulo." (fig. 7)

"Não, porque a força de atrito situa-se entre os dois blocos

blocos 2 e 3, se o atrito fosse aumentado entre estes blocos:

"Não, o movimento de (2) não será modificado se o atrito aumentar entre (2) e (3) porque $o$ atrito não age sobre $\boldsymbol{m}_{2}$, mas ele age sobre $\boldsymbol{m}_{3}$." (fig. 7 )

"O movimento de (2) não será modificado porque $F$ é constante e este movimento não depende das forças situadas em cima de $\boldsymbol{m}_{2}$." (fig. 7)

Note-se que a população que traça corretamente o par ação e reação nos diagramas de forças (forças casadas), também utiliza, não raras vezes, argumentações que se reúnem àquelas mostradas anteriormente, como mostram as citações que se seguem:

- Questionário $A_{1 c}$, questão 4, sobre a modificação ou não do movimento dos blocos 1 e 2, se o atrito fosse aumentado entre estes blocos:

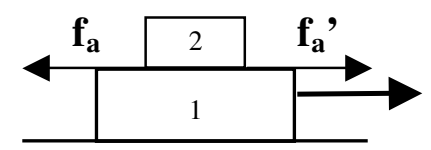

Figura 8: Forças traçadas pela população
"O movimento de (2) mudará porque a força de atrito que interfere (intervém) no seu movimento vai aumentar. $O$ movimento de (1) não mudará porque, apesar do aumento da força de atrito sobre este bloco, esta força não condiciona o seu movimento (forças simétricas)." (fig.8)

Observe-se que este estudante, ao mesmo tempo que reconhece a existência de uma força de atrito sobre o bloco "debaixo" (bloco 1), não a reconhece como força capaz de intervir (condicionar) no movimento deste (o que não ocorre quando se trata do bloco "de cima").

- Questionário $A_{2 c}$, questão 2, sobre o movimento do bloco 1:

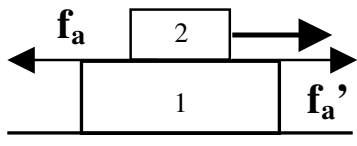

Figura 9: Forças traçadas pela população
"O bloco 1 desloca-se no mesmo sentido de $m_{2}$ porque 0 atrito $\mathbf{m e s a} / \boldsymbol{m}_{\mathbf{1}}=\mathbf{0}$. Este movimento produz-se por causa do atrito que tende a unir os blocos." (fig.9) 
Observemos a diferença entre o tipo de justificativas acima e aquelas onde a população que desenha também forças casadas declara, sem ambigüidades, que a força de atrito age nos blocos que se encontram sob a interface de contato (blocos "debaixo"):

- $\quad$ Questionário $A_{2 c}$, questão 2, sobre o movimento do bloco 1:

"O bloco de massa $\mathrm{m}_{1}$ move-se para a direita, no sentido da força de atrito de (2) sobre (1) $\left(f_{a}{ }^{\prime}\right)$. A força de atrito não se opõe ao movimento de (1), ao contrário, ela é a responsável pelo movimento do bloco." (fig. 9)

"A força de atrito sobre 1 ( $\mathrm{f}_{\mathrm{a}}$ ') é exatamente a força que Ihe imprime movimento e, portanto, ela não se opõe ao movimento. Se esta força não existisse, o bloco 2 se deslocaria livremente sobre $m_{1}$ e $m_{1}$ ficaria parado." (fig.9)

Com respeito às forças normais, relembremos que a força solitária traçada pela enorme maioria da população tem o sentido sempre orientado verticalmente para "cima" ( $\uparrow)$, isto é, é sempre a força que o bloco "debaixo" exerce sobre aquele que está "em cima": a força que o bloco "de cima" exerce sobre aquele que está "embaixo" $(\downarrow)$, jamais é traçada ou mencionada.

\section{Discussão dos resultados}

Considerando-se o substancial número de pessoas que foram interrogadas, tão diferentes, quer pela cultura de origem quer pelo nível de estudos, os resultados obtidos indicam uma forte tendência à presença de modos de raciocínio específicos, sempre que os estudantes são confrontados com situações de atrito onde dois ou mais sólidos estão em contato.

Podemos descrever sinteticamente esta tendência, analisando-a na seguinte perspectiva:

- Para a população envolvida no estudo, em presença de UM fenômeno de atrito (estático ou cinético) entre sólidos em contato, a UMA interação de contato corresponde UMA única resultante das forças de contato, isto é, UMA única componente normal e UMA única componente tangencial às superfícies de contato dos sólidos, que age somente sobre UM dos sólidos em contato, aquele que se encontra sobre a interface de contato (Quadro 1).

UM fenômeno de atrito $\rightarrow$ UMA interação de contato $\rightarrow$ UMA resultante das forças de contato $\rightarrow$ ação sobre $\mathbf{U M}$ dos sólidos em contato

Quadro 1: Resumo esquemático da tendência dos modos de raciocínio da população 
Aparentemente, aplicando este modo de raciocínio "linear", os estudantes não sentem necessidade de modelar o fenômeno do atrito por meio de duas resultantes das forças de contato, as quais formam o par ação e reação, cada uma agindo em cada um dos objetos em contato.

Assim, a população concilia o seu modelo com explicações que dão conta do movimento dos objetos, como vimos nas citações, e que podemos explicitar da seguinte forma:

- Se a força externa aplicada é exercida no bloco situado sob a interface de contato (caso, por exemplo, do bloco 1 nos questionários $A_{1}$ ), não existiria então necessidade de uma força de atrito que o bloco situado sobre a interface de contato exerceria sobre aquele situado sob esta interface, para explicar o movimento deste: a força externa está lá para explicá-lo;

- Se a força externa aplicada é exercida no bloco situado sobre a interface de contato (caso, por exemplo, do bloco 2 nos questionários $A_{2}$ ), também não existiria necessidade de uma força de atrito que o bloco situado sobre a interface de contato exerceria sobre aquele situado sob esta interface, para explicar o movimento deste: a existência de um atrito (e não de uma força de atrito) que "tende a unir" os blocos, pois "as superfícies aderem umas às outras", está lá para explicá-lo.

Esta última construção explicativa não deixa de ser surpreendente, se nos lembrarmos que uma das grandes tendências das concepções dos estudantes em Mecânica apontadas pelos diferentes pesquisadores desta área, alguns dos quais já nos referimos no início da exposição, consiste em considerar que quando um corpo se encontra em movimento, deverá existir uma força na mesma direção e sentido deste movimento.

Desta forma, o atrito parece funcionar aqui, como "algo" existente entre as superfícies em contato que assegurando uma certa "união" ou "aderência" entre estas superfícies, dispensa, assim, a necessidade de uma força que se exerça explicitamente sobre o corpo e que explique o movimento deste.

Estamos, portanto, numa outra categoria de situações e de questões, cuja diferença é a existência de atrito entre os objetos em estudo e que nos conduzem, como acabamos de mostrar, a modos de raciocínio específicos.

De outra perspectiva, a análise do conjunto das justificativas nos permite destacar um modo de raciocínio específico, o qual convencionamos chamar efeito $D-D^{8[6]}$ e que podemos modelar da seguinte forma (Quadro 2):

${ }^{8[6]}$ Do francês efeito "Dessous-Dessus" que significa literalmente "Debaixo- De cima". 


\section{Efeito D-D}

A existência de atrito entre a interface inferior (a "debaixo") de um corpo $\mathrm{X}$ e outro corpo $Y$ influencia no movimento de $X$, enquanto que $o$ atrito existente entre a interface superior (a "de cima") do corpo X e outro corpo Z não influencia no movimento de $\mathrm{X}$ :

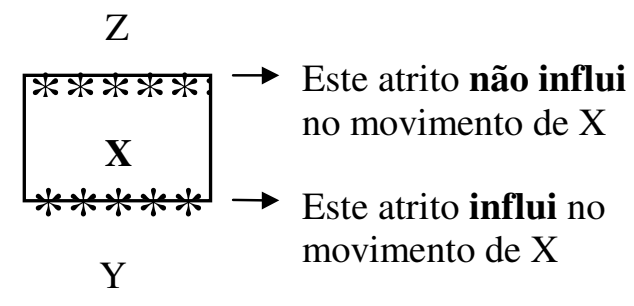

\section{Quadro 2: Modelagem do efeito D-D}

Este efeito, descrito explicitamente pelos estudantes, como foi anteriormente mostrado, é ainda apoiado ou reforçado pelos diagramas de forças, onde:

- A grande maioria da população traça somente uma força de atrito única e uma força normal única (forças solitárias);

- A força de atrito solitária jamais é traçada no bloco que se encontra sob a interface de contato (o "debaixo"): ela é desenhada na interface dos blocos ou no bloco que se encontra sobre a interface de contato (o "de cima");

- A força normal solitária desenhada é sempre aquela que o bloco "debaixo" exerce sobre o bloco "de cima" e jamais o inverso.

Lembremos, ainda, que os argumentos que caracterizam o efeito D-D, também são utilizados pela população que traça forças casadas (par ação e reação): a força que se exerceria no bloco "debaixo" é desenhada, mas não tem nenhum efeito no movimento deste bloco.

\section{Os livros}

$\mathrm{Na}$ tentativa de buscar mais subsídios para as análises e considerando as tendências dos modos de raciocínio dos estudantes descritas neste trabalho, examinamos alguns livros didáticos susceptíveis de serem utilizados por uma parte das pessoas interrogadas nesta investigação, ao longo dos seus estudos.

No total, examinamos 32 livros utilizados no Ensino Médio, Técnico e Superior Francês (Caldas, 1999) e 7 livros utilizados no ciclo básico do Ensino Superior Brasileiro ${ }^{9[7]}$, nos debruçando objetivamente sobre dois pontos, dados os resultados obtidos nos questionários:

${ }^{9[7]}$ Referências bibliográficas em "Anexos". 
- Nos capítulos ou itens dos livros reservados ao estudo do atrito, as forças de contato aparecem como forças solitárias ou casadas e em que objetos são elas aplicadas? Foram também examinados, na parte teórica, os exercícios resolvidos e os exemplos propostos sobre 0 atrito.

Assim, as análises mostraram que:

- Apenas em cerca de 10\% dos livros examinados aparecem desenhadas, esporadicamente, todas as ações de contato entre dois sólidos mostrando, portanto, a aplicação da $3^{\text {a }}$ lei de Newton na presença do atrito. Em todos os outros livros, nunca aparecem desenhadas todas as resultantes das ações de contato entre as duas superfícies em contato, cada uma agindo em cada superfície: aparece somente representada uma única resultante (uma única força de atrito e uma única força normal) agindo no sólido em estudo.

- As situações físicas escolhidas são tais que, estas forças solitárias são sempre aquelas que a superfície que se encontra sob a interface de contato dos sólidos (a "debaixo") exerce sobre aquela que se encontra sobre esta interface (a "de cima").

- Os exercícios e exemplos abordados na parte teórica estudam apenas, na maioria quase absoluta dos livros, situações físicas nas quais um sólido move-se horizontalmente (ou pode eventualmente entrar em movimento) numa superfície fixa em relação ao referencial dado.

- A força de atrito única é majoritariamente representada na interface de contato.

Assim, para a grande maioria dos livros, a terceira lei de Newton jamais aparece nos diagramas de força ou na parte teórica ou ainda nos exemplos propostos, existindo um "sentido" privilegiado para a representação das forças, aquele "debaixo" para "cima".

Como a única força desenhada na interface (e estudada), é aquela que o corpo situado sob a interface de contato, exerce sobre o corpo situado sobre esta interface, não é difícil de interpretar que, a uma interface de contato corresponde uma única força de atrito e uma única força normal, forças estas que agem sempre no corpo que está sobre as interfaces de contato (efeito D-D).

Em resumo, constatamos que, para a grande maioria dos livros, assim como para os estudantes, o fenômeno de atrito (estático ou cinético) é representado por uma única resultante das ações de contato (forças solitárias), localizadas na interface de contato dos corpos e exercendo-se no sólido que se move ou tem a possibilidade de se mover sobre esta interface.

Desta forma, só podemos concluir que, na melhor das hipóteses, os estudantes encontram na grande maioria dos livros didáticos elementos que alimentam o tipo de resultados encontrados.

\section{Conclusão}

Os resultados aqui discutidos são largamente partilhados por uma população importante e bastante variada, fato que nos parece um argumento importante para que eles sejam levados em conta no ensino em geral.

Por outro lado, a análise dos diferentes livros didáticos mostra que as opções da quase totalidade dos seus autores não incluem nenhuma preocupação com os aspetos levantados 
neste estudo e, muito pelo contrário, as abordagens por eles escolhidas só tendem a reforçálos.

Constatamos, em resumo, que para a grande maioria da população alvo do estudo, assim como, na grande maioria dos livros analisados, o fenômeno de atrito de escorregamento (atrito cinético ou dinâmico) e de não escorregamento (atrito estático) é representado ou modelado por uma resultante única das forças de contato (não aplicação da $3^{a}$ lei de Newton), preferencialmente localizada na interface de contato dos sólidos ("entre" os sólidos) e com uma orientação bem definida de ação, sempre do sólido que se encontra sob esta interface sobre o sólido que se encontra sobre ela (efeito D-D).

As construções explicativas dos estudantes que justificam o conjunto de resultados acima resumidos, procuram conciliar a consideração da existência de uma única força de atrito quando dois sólidos estão em contato e que não age senão sobre o sólido que está sobre a superfície de contato, com o movimento ou o eventual movimento de um objeto, inicialmente em repouso, sem que nenhuma força no sentido do movimento se exerça explicitamente sobre ele.

Esta conciliação é possível, pois, para os estudantes, o atrito parece funcionar como um "agente mediador" entre os objetos em contato, que assegurando entre eles um "elo" ou uma "ligação" com propriedades mais ou menos "aderentes", é capaz de provocar o movimento do objeto estudado sobre o outro que lhe serve de suporte, sem que haja a necessidade da ação explícita de uma força sobre aquele.

Como já comentamos anteriormente, este modo de raciocínio é a priori incompatível com os resultados obtidos em inúmeros trabalhos (entre os já referidos, ressaltamos aqui os trabalhos de Viennot em Dinâmica), os quais colocam em evidência que os estudantes tendem a considerar que um movimento num determinado sentido implica necessariamente na existência de uma força no mesmo sentido.

A diferença essencial entre as situações de dinâmica geralmente propostas nesses trabalhos e aquelas estudadas aqui, é que estas estão centradas na existência de atrito entre dois ou mais objetos em contato. Este fato sugere que a presença desse fenômeno provoca o desencadeamento de modos de raciocínio específicos, ao que parece, fortemente relacionados com um conceito de atrito sem ressonância com a visão científica.

De outra perspectiva, os resultados encontrados mostram, também, que ignorar a $3^{\text {a }}$ lei de Newton tem conseqüências deveras indesejáveis na modelagem do fenômeno do atrito e ressaltam a importância de perceber as forças de atrito como forças que, como qualquer outra, obedecem às leis de Newton.

Como conseqüência, o conjunto de resultados desta investigação permite-nos formular algumas sugestões ou recomendações pedagógicas que visam fornecer subsídios para a prática de ensino sobre o tema do atrito sólido seco, procurando ressaltar os aspectos que nos parecem suscetíveis de contribuir para, no mínimo, não reforçar as tendências dos modos de raciocínio dos estudantes aqui evidenciadas.

Nesse contexto, parece-nos bastante recomendável no estudo e ensino do atrito levar em consideração determinados pontos, salientando-se que estes não podem inserir-se no âmbito deste trabalho senão enquanto sugestões a validar em pesquisas futuras:

- Modelar sem ambigüidades o fenômeno do atrito, associando-o às resultantes das forças de contato que cada uma das superfícies em contato exerce sobre a outra; 
- Discutir claramente sobre qual objeto cada força de atrito é exercida, inserindo exemplos em que dois ou mais sólidos estão em contato, alargando o espectro de exemplos da grande maioria dos livros didáticos (um corpo deslocando-se sobre uma superfície fixa);

- Discutir a aplicação da 3a lei de Newton procurando metodicamente o par de cada força "solitária": as forças de contato horizontais ou verticais são exercidas sobre cada sólido em contato (mesmo se estas forças estão 'localizadas' na interface de contato dos sólidos), qualquer que seja a posição dos sólidos uns em relação aos outros.

- Opção, como método normal de trabalho, de representar as forças exercidas nos objetos em estudo no que habitualmente se chama de "diagramas de corpo livre" (diagramas de corpos separados). As vantagens deste tipo de diagramas parecem óbvias, pois "força" a localização de cada força sobre cada objeto.

Parece também prudente, tendo em conta os resultados obtidos, que os autores dos livros didáticos quando representam as forças de atrito nos objetos em estudo (normalmente blocos), as localizem num ponto vizinho da interface de contato (portanto, aplicadas claramente sobre o objeto), e não nesta interface, caso não se faça a opção sistemática pelos "diagramas de corpo livre".

Este último ponto relaciona-se com a questão da definição dos contatos, assunto abordado no quadro teórico inicialmente delineado; o conjunto das análises desenvolvidas levanos a refletir, que talvez este aspecto deva anteceder o estudo das forças de contato aqui tratadas, o que não é feito em geral nos livros ou nas práticas correntes de ensino, pois o estudo sugere que não parece ser tão trivial para os estudantes distinguir os pontos de contato geométricos, dos pontos materiais que, embora coincidindo com aqueles num dado instante, pertencem a cada uma das superfícies em contato.

Consequentemente, parafraseando Viennot (1989), "fixar" as forças (aqui, de atrito) na interface de contato dos sólidos, embora seja o que grande parte dos livros promove, não parece ser uma metodologia adequada e suficiente para distinguir sobre que objetos as forças agem.

Finalmente, os resultados do trabalho sugerem que, no geral, o estudo do atrito sólido seco constitui-se numa boa e, pelo que aqui relatamos, muito necessária ocasião para rever e insistir na problemática que envolve a terceira lei de Newton, fonte de inesgotáveis dificuldades dos estudantes.

\section{Referências Bibliográficas}

BOYLE, R. K. \& MALONEY, D. P. (1991). Effet of written text on usage of Newton's third law. Journal of Research in Science Teaching. 28 (2) : 123-140.

CALDAS, H. (1999). Atrito: o que diz a Física, o que os alunos pensam e o que os livros explicam. Edufes, Vitória, ES, Brasil.

MALONEY, D. P. (1984). Rule-governed approaches to physics: Newton's third law. Physics Education. 19: 37-42.

MENIGAUX, J. (1986). La schématisation des interactions en classe de troisième. Bulletim de l'Union des Physiciens. 683: 761-778.

OGBORN, J. (1985). Understanding students' understandings: an example from dynamics. European Journal of Science Education. 7 (2): 141-150. 
SALTIEL, E. \& MALGRANGE, J. L. (1980). 'Spontaneous' ways of reasoning in elementary mechanics. European Journal of Physics. 1: 73-80.

TERRY, G. J. \& SALTIEL, E. (1985). Children's conceptual understanding of forces and equilibrium. Physics Education. 20 (4): 162-165.

THORNTON, R. K. \& SOKOLOFF, D. R. (1998). Assessing student learning of Newton's law: the force and motion conceptual evaluation and the evaluation of active learning laboratory and lecture curricula. American Journal of Physics. 66: 338-352.

WHITELOCK, D. (1991). Investigating a model of commonsense thinking about cause of motion with 7 to 16 years old pupils. International Journal of Science Education. 13 (3): 321-340.

VIENNOT, L. (1979). Le raisonnement spontané en dynamique élémentaire. Hermann, Paris.

VIENNOT, L. (1989). Bilan de forces et loi des actions réciproques. Analyse des difficultés des élèves et les enjeux didactiques. Bulletim de l'Union des Physiciens. 716: 951-970.

VIENNOT, L. (1996). Raisonner en physique. La part du sens commun. De Boeck Université, Paris. 


\section{Anexos}

\section{Questionários:}

\begin{tabular}{|c|c|}
\hline$A_{1 c}$ & $A_{2 C}$ \\
\hline 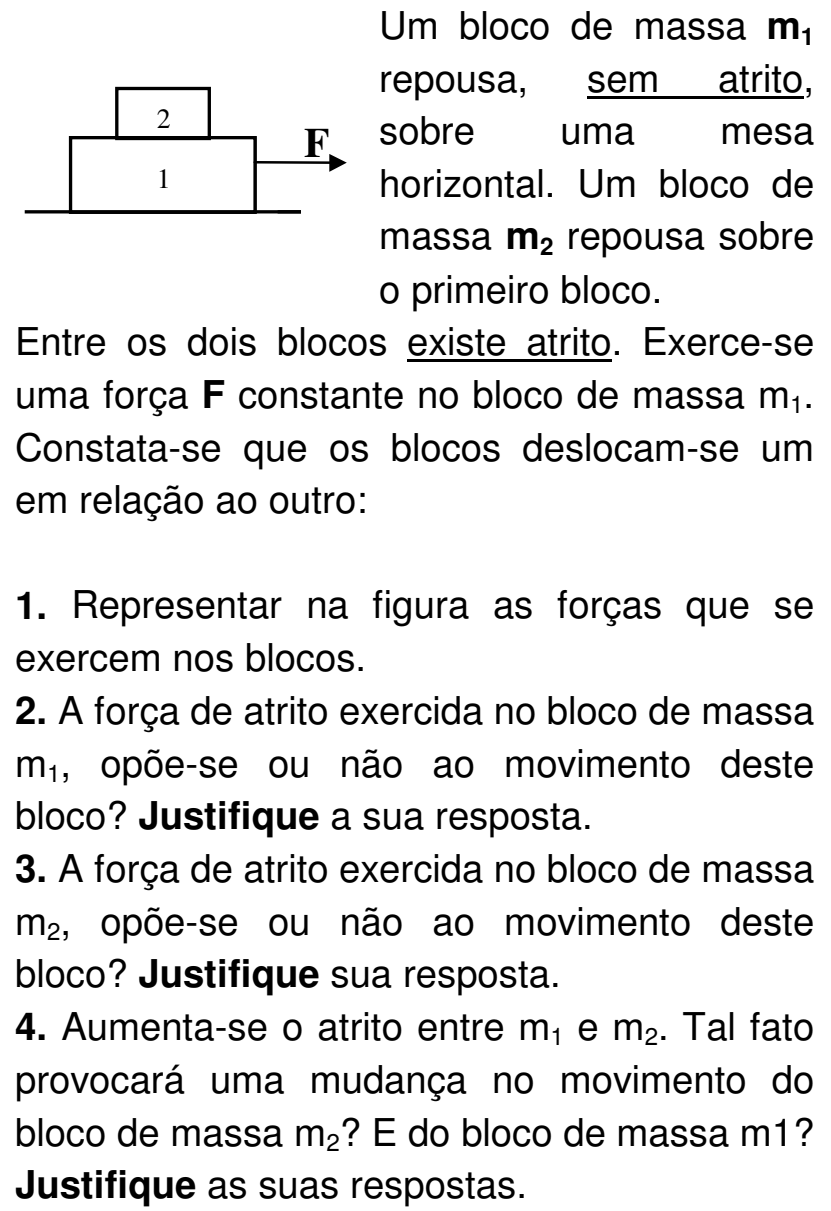 & $\begin{array}{l}\text { Um bloco de massa } \mathbf{m}_{1} \\
\begin{array}{l}\text { repousa, } \\
\text { sobre uma mem atrito, } \\
\text { horizontal. Um bloco de } \\
\text { massa } \mathbf{m}_{2} \text { repousa sobre } \\
\text { o primeiro bloco. }\end{array} \\
\text { Entre os dois blocos existe atrito. Exerce-se } \\
\text { uma força } \mathbf{F} \text { constante no bloco de massa } \mathrm{m}_{1} \text {. } \\
\text { Constata-se que os blocos deslocam-se um } \\
\text { em relação ao outro: } \\
\text { 1. Representar na figura todas as forças } \\
\text { verticais e horizontais que se exercem em } \\
\text { cada um dos blocos. } \\
\text { 2. Qual é o sentido do movimento do bloco de } \\
\text { massa } \mathrm{m}_{1} \text { em relação à mesa? A força de } \\
\text { atrito exercida neste bloco, opõe-se ou não ao } \\
\text { movimento do bloco. Justifique a sua resposta. } \\
\text { 3. Qual é o sentido do movimento do bloco de } \\
\text { massa } \mathrm{m}_{2} \text { em relação à mesa? A força de } \\
\text { atrito exercida neste bloco, opõe-se ou não ao } \\
\text { movimento do bloco em relação à mesa? } \\
\text { Justifique as suas respostas. }\end{array}$ \\
\hline
\end{tabular}




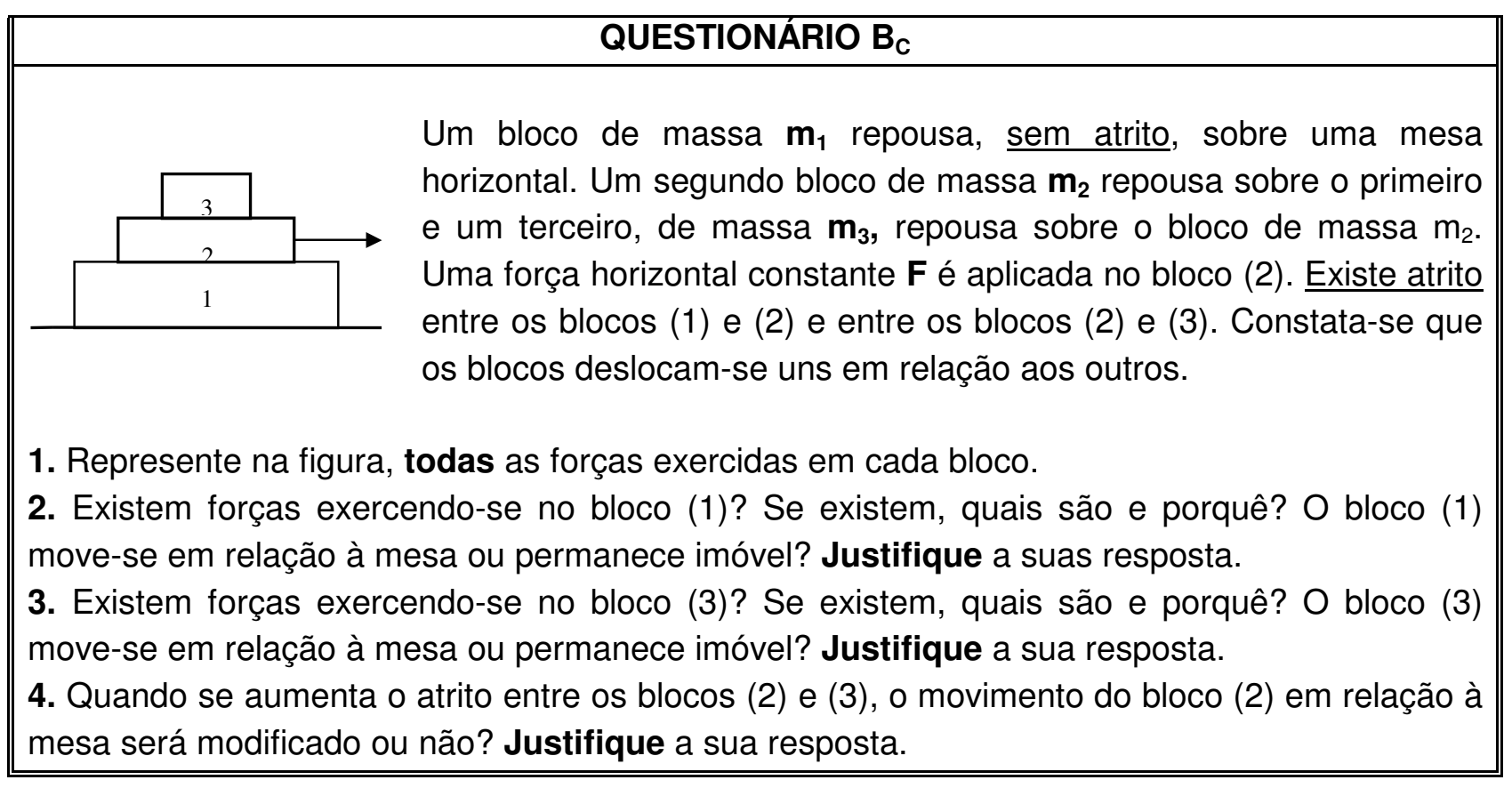

\section{- Referências bibliográficas dos livros utilizados no ciclo básico do Ensino Superior Brasileiro}

ALONSO M. \& FINN E. J., 1972. Física: um curso universitário, volume 1 - Mecânica. Edgard Blucher Ltda., São Paulo.

EISBERG R. M. \& LERNER L. S., 1982. Física: fundamentos e aplicações, volume 1 (4 $^{\text {a }}$ edição). McGraw-Hill do Brasil, São Paulo.

HALLIDAY D., RESNICK R. \& WALTER J., 1996. Fundamentos de Física: Mecânica, volume 1. Livros Técnicos e Científicos Editora S.A., Rio de Janeiro.

McKELVEY J. P. \& GROTCH H., 1979. Física, volume 1. Harbra, Editora Harper \& Row do Brasil Ltda., São Paulo.

NUSSENZVEIG H. M., 1987. Curso de física Básica, 1 - Mecânica. Edgard Blucher Ltda., São Paulo.

SEARS F., ZEMANSKY M. W. \& YOUNG H. D., 1999. Física 1: Mecânica da Partícula e dos Corpos Rígidos (2a edição). Livros Técnicos e Científicos Editora S.A., Rio de Janeiro.

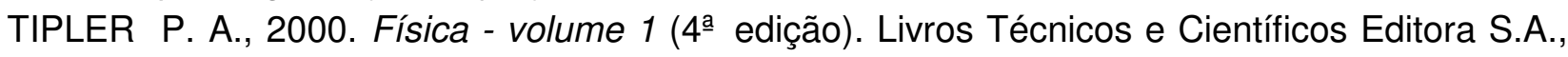
Rio de Janeiro.

\section{Agradecimentos}

Gostaríamos de agradecer a H. Richoux, U. Besson e J.-C. Bernard pela participação nas nossas investigações sobre a problemática do atrito, no contexto do Tutorado de Didactique des Sciences Physiques do DEA, na Universidade de Paris VII. 